\title{
More Research Results
}

\begin{abstract}
We asked our experts what they think might be the reason for all those never caught or convicted: Is it because they are never detected, never investigated, never prosecuted, or because they are never convicted? All respondents agree that detection is the major reason for lack of law enforcement. Only 8 percent of white-collar criminals convicted to prison in Norway from 2009 to 2015 are women. On average, experts believe that 6.5 percent of all female offenders are caught, while 10.5 percent of all male offenders are caught. Experts confirm in this study that detection of white-collar crime is dependent on gender. Male criminals are detected more frequently than females. One explanation for this gender gap is the lack of suspicion towards female offenders.
\end{abstract}

Keywords Confirmation trap $\bullet$ Conviction - Criminal population size

- Detection • Female offenders • Gender gap • Investigation • Pinkcollar criminals • Prosecution • Variation in responses

In a previous chapter, we applied expert elicitation to estimate the amount of money lost from white-collar crime every year in Norway. The panel of experts was asked to estimate the magnitude of white-collar crime as well as reasons for the lack of convictions.

The visible tip represents around 10 percent of the total iceberg, as suggested by our experts.

(C) The Author(s) 2018

P. Gottschalk, L. Gunnesdal, White-Collar Crime in the Shadow Economy, https://doi.org/10.1007/978-3-319-75292-1_6 
We asked all our experts for an opinion on why people are not caught or convicted: Is it because they are never detected? Is it because they are never investigated? Is it because they are never prosecuted? Is it because they are never convicted?

\section{Lack of Detection and Conviction}

We asked respondents to distribute the remaining percentages from 100 percent after subtracting 9.4 percent for those caught and convicted. The average response from 15 experts is as follows:

- Lack of detection: 59 percent. For example, it may be easy to commit financial crime and to hide illicit transactions among legal transactions. There may also be a consensus culture at board level whereby management is not being asked critical questions and is thus avoiding transparency and control. One respondent said: "The police always complain that they are lacking resources, but I also think that detectives are not good enough." Another respondent pointed out that there are "powerful forces that prevent people from whistleblowing".

- Lack of investigation: 19 percent. The police do not have the capacity and must therefore dismiss criminal cases. One respondent pointed out that although lack of detection is a problem, she had noted that the police dismiss many cases. Nineteen percent of all white-collar criminals are assumed to be detected, but not investigated, although they are guilty.

- Lack of prosecution: 8 percent. The police do not have competence and are therefore not successful in obtaining evidence sufficient to get likely convictions. Eight percent of all white-collar criminals are assumed to be detected and investigated, but not prosecuted, although they are guilty.

- Lack of conviction: 5 percent. Defense attorneys are often successful in their substance, defense, symbolic defense, and information control. Prosecutors tend to be legal generalists, while defense attorneys tend to be white-collar crime specialists. Judges in court are afraid of miscarriages of justice, so prefer to acquit a guilty person rather than convict a possibly innocent person. Five percent of all white-collar criminals are assumed to be detected, investigated and prosecuted, but not sentenced, although they are guilty. 
It is interesting to note that all respondents agree that detection is the major reason for the lack of law enforcement. While their estimates vary, lack of detection is the main reason for all respondents, varying from 40 percent to 90 percent with an average of 59 percent. The expert with the highest estimate is an internal revenue executive at the Norwegian Tax Administration, while the expert with the lowest estimate is an investment banker. This implies that the investment banker believes in a much higher detection rate for white-collar criminals, which is indeed the case given the investment banker's response to the first question.

Given that 59 percent of all white-collar criminals are never detected, a challenging responsibility rests with professionals who are supposed to detect financial crime. These professionals include internal and external auditors, compliance officers, audit committees, and management at all levels.

When offenders are detected, they may nevertheless not be investigated. The fraction not investigated varies from 3 percent to 30 percent. The bankruptcy auditor is the one who believes that many detected criminal cases are never investigated, indicating that almost one-third of all white-collar criminals belong in this category. The bank executive shares this opinion. The average response is 19 percent in this category, which is surprisingly high, indicating that experts think that the police are often reluctant to look into white-collar crime cases.

When offenders are detected and then investigated, they may nevertheless not be prosecuted. They are assumed to be guilty, but prosecutors decide not to bring them to court as defendants, maybe because of lack of evidence. Experts estimate this population fraction to range from 1 percent to 20 percent. It is the private investigator who believes in a figure of 20 percent, while it is the internal revenue executive who believes in only 1 percent. The average is 8 percent.

When offenders are guilty and defending themselves in court, they may nevertheless not be convicted. Experts estimate this population fraction to range from 1 percent to 10 percent. Again, the private investigator believes in the highest fraction, this time of guilty criminals whose cases are dismissed. And again, it is the internal revenue executive who believes in the lowest fraction (i.e., this expert believes that almost all guilty defendants in court are sentenced). The average is $\mathbf{5}$ percent. 


\section{Example: An InVESTigative Journalist}

To illustrate the variation in responses to our seven expert elicitation approaches, we select an investigative journalist, since investigative journalists are credited with the most detections of white-collar crime. Table 6.1 shows the journalist's estimates resulting from the seven approaches.

It is interesting to note that while this expert suggests a fraction of 8 percent, all levels of offenders have a higher detection rate-according to the expert-as illustrated in approach 3. Furthermore, this expert disagrees with other experts, as he believes that the detection rate for male and female offenders is the same.

Table 6.1 Seven different expert estimations of the magnitude of white-collar crime

\begin{tabular}{lcc}
\hline $\begin{array}{l}\text { Estimation technique for the } \\
\text { magnitude of white-collar } \\
\text { crime }\end{array}$ & $\begin{array}{l}\text { Fraction of offender } \\
\text { population canght and } \\
\text { convicted (\%) }\end{array}$ & $\begin{array}{c}\text { Magnitude of white- } \\
\text { collar crime (billion } \\
\text { NOK) }\end{array}$ \\
\hline 1 Fraction of total & 8 & 14.2 \\
2 Fraction, probability & 10 & 11.0 \\
distribution & & \\
- Level 1 & 13 & 4.4 \\
- Level 2 & 23 & 2.0 \\
- Level 3 & 30 & 0.5 \\
Groups of offenders & & 6.9 \\
- Fraud & 15 & 4.2 \\
- Theft & 5 & 0.2 \\
- Manipulation & 5 & 9.4 \\
- Corruption & 5 & 0.5 \\
Groups of offences & & $\mathbf{1 4 . 3}$ \\
- Employer & 20 & 0.7 \\
- Tax & 20 & 2.0 \\
- Bank & 5 & 4.9 \\
- Customer & 10 & 1.7 \\
- Shareholder & 5 & 2.6 \\
- Other & 15 & 0.3 \\
Groups of victims & & $\mathbf{1 2 . 2}$ \\
- Female & 8 & 0.5 \\
- Male & 8 & 13.7 \\
Gender & & $\mathbf{1 4 . 2}$ \\
Estimate of total amount & & $\mathbf{1 0 . 0}$ \\
Average magnitude & & 1.8 \\
\hline
\end{tabular}




\section{Criminal Population Size}

About 58 white-collar criminals are convicted to prison every year in Norway. We assume this is 9.4 percent of the total criminal population. Thus, the total population is estimated at 617 offenders per year who commit financial crime that year.

The estimation of total population size for various phenomena of crime is an important factor that is critical for criminal justice policy and priorities in law enforcement. Rossmo and Routledge (1990) discuss methods for estimating the size of a criminal population from police records. This is similar to our estimation based on convicted white-collar criminals. In their research, they found that police records are virtually unaffected by a potentially large pool of criminals as they tried to predict the size of population for migrating (or fleeing) fugitives and for street prostitutes.

\section{Gender Perspectives on Crime}

Only 8 percent of white-collar criminals imprisoned in Norway from 2009 to 2015 are women. Ninety-two percent are men. In a number of research articles, it has been speculated why the female fraction is so low. Interestingly, our experts unknowingly indicated a similarly low female fraction by providing an average estimate of 6.5 percent female detection rate.

In terms of gender, experts responded as follows:

1. An investigative journalist stated that 8 percent of female offenders and 8 percent of male offenders are detected-thus implying no gender gap.

2. A bankruptcy attorney stated that 5 percent of female offenders and 3 percent of male offenders are detected-thus a gender gap favoring the detection of women.

3. An internal auditor stated that 2 percent of female offenders and 7 percent of male offenders are detected-thus a gender gap favoring the detection of men.

4. A tax clerk in the internal revenue service stated that 5 percent of female offenders and 20 percent of male offenders are detectedthus a gender gap favoring the detection of men.

5. A tax clerk in the internal revenue service stated that 5 percent of female offenders and 5 percent of male offenders are detectedthus implying no gender gap. 
6. A tax clerk in the internal revenue service stated that 3 percent of female offenders and 7 percent of male offenders are detectedthus a gender gap favoring the detection of men.

7. A bank manager stated that 10 percent of female offenders and 10 percent of male offenders are detected-thus implying no gender gap.

8. A bank manager stated that 3 percent of female offenders and 3 percent of male offenders are detected-thus implying no gender gap.

9. A police investigator stated that 10 percent of female offenders and 25 percent of male offenders are detected-thus a gender gap favoring the detection of men.

10. A corruption researcher stated that 3 percent of female offenders and 8 percent of male offenders are detected - thus a gender gap favoring the detection of men.

11. A private investigator stated that $\mathbf{1 5}$ percent of female offenders and 23 percent of male offenders are detected-thus a gender gap favoring the detection of men.

12. A private investigator stated that 5 percent of female offenders and 4 percent of male offenders are detected-thus a gender gap favoring the detection of women.

13. A corporate investor meant that 30 percent of female offenders and 30 percent of male offenders are detected-thus implying no gender gap.

14. A defense attorney stated that 10 percent of female offenders and 10 percent of male offenders are detected-thus implying no gender gap.

15. A social security manager stated that 1 percent of female offenders and 5 percent of male offenders are detected - thus a gender gap favoring the detection of men.

The panel of experts provides no coherent response. Rather, experts disagree both in terms of percentages and in terms of relative percentages. Out of 15 experts, six believe there is no gender gap, two believe that more women than men are detected, while seven believe that more men than women are detected. The last result seems to be a common view among both researchers and practitioners, as discussed in the literature.

On average, experts believe that 6.5 percent of all female offenders are caught, while 10.5 percent of all male offenders are caught. Again, this is 
in line with common understanding. We know that 8 percent of all convicted white-collar (pink-collar) criminals in Norway are women. If we assume that their relative detection rate is only a fraction of the male detection rate $(6.5 / 10.5)$ then we can assume that the real female offender fraction in the iceberg is around 12 percent. This means that experts suggest a 12 percent fraction of female white-collar criminals in Norway rather than the 8 percent fraction of female offenders detected.

This section is not concerned with the general gender gap as such in white-collar crime, where women commit less white-collar crime compared to men. Reasons for the general gender gap include lack of opportunity, lack of motive, and lack of rationalization (Holtfreter 2015; Steffensmeier et al. 2013).

Rather, this section is concerned with the lack of detection of female white-collar criminals. The relative lack of detection can be explained by several factors. First, women are to a lesser extent suspected of financial crime. The environment is generally less suspicious of women than of men, and tends to decriminalize women. To the extent a crime is detected, a woman is not considered or treated as the main suspect. She is either treated as a criminal follower or as a criminal victim in a typical criminal investigation when there are more people involved in the crime. Detection risk is linked to general reasons why women to a far lesser extent than men are convicted of white-collar crime, namely that women generally are not convicted of crime when compared to men.

A simple experiment we have often performed with different audiences is based on the question: Who would you bribe? You would like to build a new home on a property that is designated for public recreation. You have the choice of bribing a female or male official in the municipality. Considering all the audiences over the years, a large majority vote almost exclusively to choose men. Almost no one would bribe a female official. There are two learning points here. First, very few people think that a woman is corrupt, thereby reducing the detection rate. Second, because almost no one would bribe a woman, then a woman has less opportunity to be a criminal.

Possibly women are smarter criminals than men. Again, when an experiment is carried out with an audience, most agree with this statement. One reason for relative smartness is that women may tend to stop criminal activities before it is too late. They are considered smart and manipulative and often get their way using indirect means. Women are usually brought up and thought of as the weaker sex in society and thus have to resort to 
other ways to accomplish things. It may seem that they only do work and carry out tasks that are important for the company to get done, while men only do what they would like to do. Women monopolize areas in which they seem innocent, such as care, health, and environment. Women tend to talk most passionately about ethics, morals, and social responsibility, so it is almost impossible for others to think that they are criminals. Thus, the detection fraction for women will be lower than for men. The fact that women talk most often about ethics is confirmed by a study carried out by Dodge (2009). She refers to her Canadian study in which 94 percent of all companies with an executive board with three or more female members had established guidelines for conflicts of interest. Studies such as this can help confirm that women, to a greater extent than men, are concerned that their company should follow rules and policy lines to develop and maintain a good reputation.

Some researchers make the distinction between ethics and being ethical. Research by O'Fallon and Butterfield (2005) shows no difference between women and men when it comes to making ethical and unethical decisions. Dollar et al. (2001) found, nevertheless, that a greater fraction of women in parliament is associated with a lower extent of corruption. But here, detection rate can play a role. Research findings that women are more preoccupied with ethics and demonstrate stronger ethical attitudes than men is confirmed in earlier studies as well.

Lower relative detection rate can also be explained by the tendency that white-collar crime only captures financial crime of a large magnitude. This leads to a smaller female detection fraction because the average monetary amount in female crime tends to be lower than the average amount in male crime. In addition, women may be cleverer in staying below the radar and avoiding attention by keeping quiet and stopping criminal activities at an earlier stage. A relatively low detection rate might also be explained because investigators and detectives misunderstand female roles in crime and tend to perceive women as victims of crime. Women typically present themselves as victims by claiming to be coerced by men.

On the other hand, men have a reputation of being the gender that takes initiatives at high risk and, therefore, they are more easily detected. They are also detected because they like to show off their material success. The police also contribute to the low detection fraction for white-collar female criminals compared with other kinds of crime. When the police 
attend a family because of a domestic crisis, the main suspect is almost always the man, and the man is typically removed from the situation. Likewise, if the police find incriminating documents in the home, it is assumed that they belong to the man.

From a historical perspective, society has accepted a gender culture in which it is more usual for men to be criminals. This can be explained by the confirmation trap, in which humans tend to try to confirm what they already think they know. When there are so few convicted women, then there must be fewer female criminals. When there are fewer female criminals, the police will pursue male criminals. When female criminals are not pursued, then fewer women will be convicted.

Yet another reason for a relatively lower detection fraction is that organizations internally treat suspicion as well as detection differently for men and women. Maybe it is because it is more usual for the board, management, and auditors to hand cases of male misconduct and crime over to the police. One might be more cautious and afraid of taking the wrong steps in terms of discrimination by accusing female employees of crime. It can be very convenient to forget about female misconduct and concentrate on male misconduct in internal investigations. Finally, it can be argued that traditional investigations are more suited to male suspects than to female suspects.

While some women may stop in time and not be detected, men typically have a longer criminal career than women. However, it is not easy to tell exactly when a criminal career should be described as finished or terminated, and there is little evidence in the literature. It has been suggested that women's average criminal careers last just under five years, and men's more than seven years.

In conclusion, experts confirm in this study that detection of whitecollar crime is dependent on gender. Male criminals are detected more frequently than females. One explanation for this gender gap is the lack of suspicion towards female offenders. Women are often considered more ethical. In organizations, one might be more cautious and afraid of taking the wrong steps in terms of discrimination by accusing female employees of crime. It can also be very convenient to forget about female misconduct and concentrate on male misconduct in internal investigations. Finally, it can be argued that traditional investigations are more suited to male suspects than to female suspects. 


\section{REFERENCES}

Dodge, M. (2009). Women and White Collar Crime. New York: Prentice Hall. Dollar, D., Fisman, R., \& Gatti, R. (2001). Are Women Really the "Fairer" Sex? Corruption and Women in Government. Journal of Economic Behavior \& Organization, 46(4), 423-429.

Holtfreter, K. (2015). General Theory, Gender-Specific Theory, and White-Collar Crime. Journal of Financial Crime, 22(4), 422-431.

O'Fallon, M., \& Butterfield, K. D. (2005). A Review of the Empirical Ethical Decision-Making Literature: 1996-2003. Journal of Business Ethics, 59(4), 375-413.

Rossmo, D. K., \& Routledge, R. (1990). Estimating the Size of Criminal Populations. Journal of Quantitative Criminology, 6(3), 293-314.

Steffensmeier, D., Schwartz, J., \& Roche, M. (2013). Gender and Twenty-FirstCentury Corporate Crime: Female Involvement and the Gender Gap in EnronEra Corporate Frauds. American Sociological Review, 5, 1-12.

Open Access This chapter is licensed under the terms of the Creative Commons Attribution 4.0 International License (http://creativecommons.org/licenses/ by $/ 4.0 /$ ), which permits use, sharing, adaptation, distribution and reproduction in any medium or format, as long as you give appropriate credit to the original author(s) and the source, provide a link to the Creative Commons license and indicate if changes were made.

The images or other third party material in this chapter are included in the chapter's Creative Commons license, unless indicated otherwise in a credit line to the material. If material is not included in the chapter's Creative Commons license and your intended use is not permitted by statutory regulation or exceeds the permitted use, you will need to obtain permission directly from the copyright holder.

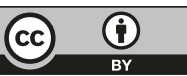

